\title{
Management of ureteral obstruction in crossed fused renal ectopia: A case report
}

\author{
Nicholas Bhojwani, MD; Jason Brett Hartman, BA; Manzoor Ahmed, MD; ${ }_{;}^{\dagger}$ Robert Morgan, $B S_{;}^{\dagger *}$ \\ Jon C. Davidson, $M D^{\S}$
}

${ }^{*}$ Department of Radiology, University Hospitals Case Medical Center, Cleveland, $\mathrm{OH} ;{ }^{\dagger}$ Case Western Reserve University School of Medicine, Cleveland, OH; §Division of Vascular and Interventional Radiology, University Hospitals Case Medical Center, Cleveland, $\mathrm{OH}$; ${ }^{*}$ Explorys Inc., Cleveland, $\mathrm{OH}$

Cite as: Can Urol Assoc J 2014;8(9-10):e752-4. http://dx.doi.org/10.5489/cuaj.2050 Published online October 22, 2014.

\section{Abstract}

Crossed fused renal ectopia is a rare congenital malformation. We describe a case in which a 58-year-old male with left-sided crossed fused renal ectopia presented with urinary bladder outlet obstruction due to metastatic prostate adenocarcinoma. Glomerular filtration rate (GFR) was $13 \mathrm{~mL} / \mathrm{min}$, creatinine $4 \mathrm{mg} / \mathrm{dL}$, and blood urea nitrogen (BUN) $58 \mathrm{mg} / \mathrm{dL}$. The patient underwent successful imageguided placement of percutaneous nephrostomy tubes which were later converted to nephroureteral stents. Labs improved to a GFR of $28 \mathrm{~mL} / \mathrm{min}$, creatinine of $2.4 \mathrm{mg} / \mathrm{dL}$, and BUN of $41 \mathrm{mg} / \mathrm{dL}$. In this case standard image-guided renal decompression techniques were effective in treating a patient with crossed fused renal ectopia.

\section{Introduction}

Crossed fused renal ectopia is the second most common renal congenital malformation, occurring in $0.01 \%$ of births(1). Patients with prostate cancer develop ureteral obstruction in $3 \%$ to $16 \%$ of cases(2), often resulting in hydroureteronephrosis and obstructive postrenal azotemia, the latter leading to renal failure. Few reports have examined the management of ureteral obstruction in crossed fused renal ectopia. We present a case of bilateral ureteral obstruction due to prostate cancer in a patient with right to left crossed fused renal ectopia-specifically Type A (inferior crossed fusion), in which standard decompression techniques were effective.

\section{Case report}

A 58-year-old male had a medical history of metastatic, hormone sensitive prostate adenocarcinoma, diagnosed 18 months prior (Gleason grade $4+4=8$ at diagnosis) and chronic renal insufficiency. He presented with outlet obstruction resulting in hydronephrosis. On physical exam vital signs were within normal limits. The abdomen was non-tender with left abdominal fullness and no costovertebral angle tenderness. Labs revealed a glomerular filtration rate (GFR) of $13 \mathrm{~mL} / \mathrm{min}$, creatinine of $4 \mathrm{mg} / \mathrm{dL}$, blood urea nitrogen (BUN) of $58 \mathrm{mg} / \mathrm{dL}$, and prostate-specific antigen of $330 \mathrm{ng} / \mathrm{mL}$. The kidney was anatomically consistent with crossed fused ectopia, with an upper pole moiety draining to the left side of the bladder and a lower pole moiety draining to the right side of the bladder (Fig. 1).

In consideration of the patient's unusual anatomy, interventional radiology was consulted to place 2 percutaneous nephrostomy tubes (Fig. 2) with a plan to follow-up with urology for retrograde stent placement if the nephrostomy tubes proved effective. Under ultrasound guidance with the patient prone a 20-gauge needle was placed into a midpole calyx of the upper pole moiety. This revealed a markedly hydronephrotic dilated collecting system. A guidewire was then advanced into the central collecting system and the tract was dilated to accommodate an 8.5- French external nephrostomy tube (Cook Medical, Bloomington, IN). The patient was then repositioned supine and the procedure was repeated on the lower pole moiety. No complications were noted. Labs 22 days following the procedure revealed an improved GFR of $28 \mathrm{~mL} / \mathrm{min}$, creatinine of $2.4 \mathrm{mg} / \mathrm{dL}$, and BUN of $41 \mathrm{mg} / \mathrm{dL}$.

Twenty-four days after nephrostomy tube insertion, urology attempted a retrograde pyelogram with retrograde stent placement. Pancystoscopy revealed a trabeculated bladder and the ureteral orifices were not easily identified. Methylene blue in sterile water was injected into each nephrostomy tube for attempted identification of the ureteral orifice but this was unsuccessful.

After a multidisciplinary discussion, the patient elected for placement of nephroureteral stents by interventional radiology (Fig. 3). Following the induction of anesthesia, the procedure was performed in 2 stages. Anesthesia was performed because of the patient's psychosocial issues. The 


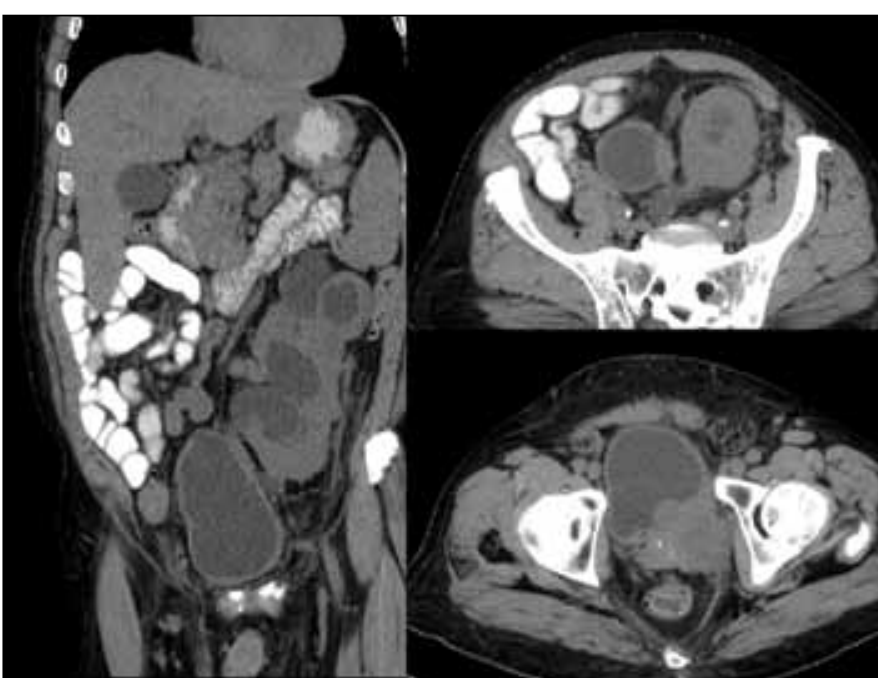

Fig. 1. Coronal and axial non-enhanced CT images demonstrate fused kidneys located within the left hemiabdomen. Hydroureteronephrosis present secondary to prostatic tumor invading the left aspect of urinary bladder and compressing the ureters. Ureter of inferior kidney inserts into right side of the urinary bladder.

details for the exchange of each nephrostomy catheter for a new stent were identical. The upper pole moiety tube was exchanged first, then the lower pole moiety stent.

Using standard techniques, a 10.2-French 24-cm Amplatz nephroureteral (NU) stent and a 10.2-French 22-cm Amplatz NU stent (Cook Medical, Bloomington, IN) were placed in the upper pole and lower pole moieties, respectively. Postprocedure contrast injections revealed that both catheters were in satisfactory position and imaging bilaterally revealed slow drainage into the bladder. It was suspected this was related to chronically dilated collecting systems. Catheters were directed to the left flank and left lower abdominal wall.

Two weeks following this procedure the patient's GFR was $31 \mathrm{~mL} / \mathrm{min}$, creatinine was $2.2 \mathrm{mg} / \mathrm{dL}$, and BUN was $35 \mathrm{mg} / \mathrm{dL}$. The nephroureteral tubes were replaced at 3 months and again at 8 months without issue. Ten months after initial renal intervention, GFR was $27 \mathrm{~mL} / \mathrm{min}$, creatinine $2.5 \mathrm{mg} / \mathrm{dL}$, and BUN $34 \mathrm{mg} / \mathrm{dL}$.

\section{Discussion}

Crossed fused renal ectopia occurs in about 1 in 1000 live births $^{3}$ and has a 3:2 male to female predominance. ${ }^{4}$ Left to right ectopia is more common than right to left. There are several classifications of crossed fused renal ectopia depending on the orientation of the fused kidneys including: unilateral fused kidney with inferior or superior ectopia, sigmoid kidney, lump kidney, disc kidney, and L-shaped kidney. ${ }^{4}$ The abnormality is the result of inappropriate development of the ureteric bud and metanephric blastema between 4 to 8 weeks gestation. It is hypothesized to be associated with caudal rotation of the embryo, which is supported by

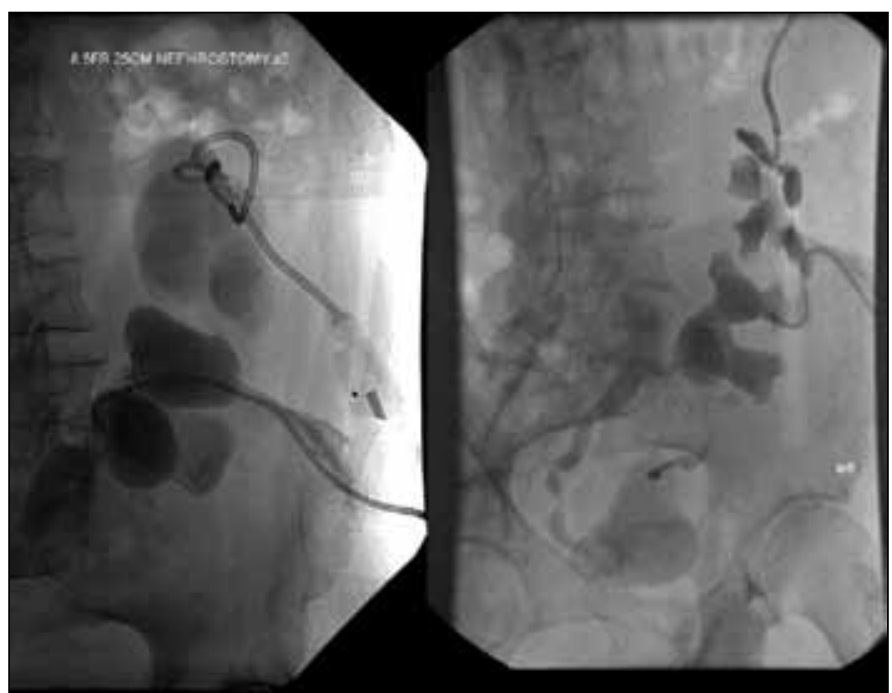

Fig. 2. Both nephrostomies seen within left abdomen/pelvis with contrast opacification of both collecting systems. Contrast seen within right ureter originating from the lower kidney. Left ureter is partially filled with contrast.

increased prevalence in patients with scoliosis. ${ }^{5}$ Associated conditions include vertebral defects, anal atresia, cardiac defects, tracheo-esophageal fistula, renal anomalies, and limb abnormalities (VACTERL), various urogenital abnormalities, and cardiovascular septal defects among others. ${ }^{5}$ In familial cases, an autosomal dominant inheritance pattern has been identified. ${ }^{6}$

Although crossed fused renal ectopia is often discovered incidentally while investigating other genitourinary issues, approximately half of all patients experience complications, such as hydronephrosis, nephrolithiasis, and frequent urinary tract infections. ${ }^{4}$ While there is no primary treatment,

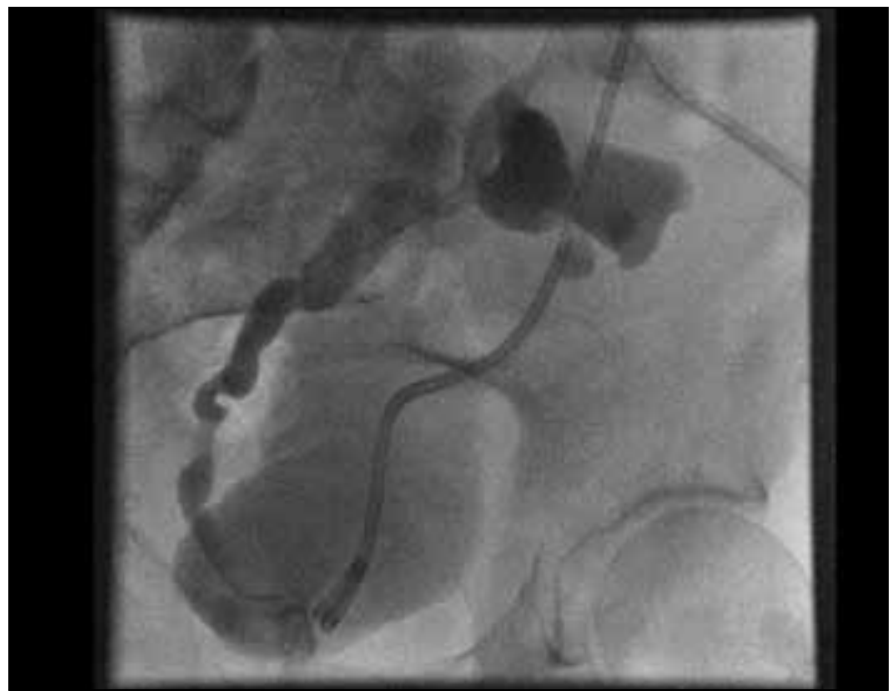

Fig. 3. Nephrostomies were eventually removed and exchanged for internalized nephroureteral stents. Upper kidney nephroureteral stent is seen already in place with a wire present within the lower kidney collecting system traversing into the urinary bladder, in process of placing the second stent. 
surgical management is important for associated problems, such as ureteropelvic junction obstruction and vesicoureteral reflux. ${ }^{4}$

Ureteral obstruction due to pelvic malignancy, notably prostate cancer, is common in the later stages of advanced disease. Patients that develop bilateral obstruction may develop hydroureteronephrosis and progressive renal failure. Bypassing the obstruction can help relieve symptoms, such as uremia, electrolyte disturbances, and recurrent urinary tract infections. ${ }^{7}$ Even with decompression, life expectancy is short in patients with advanced carcinoma, with a mean survival between 3 to 7 months. ${ }^{7-10}$

\section{Conclusion}

Few reports exist on the management of crossed fused renal ectopia. This case provides an example of using standard image-guided renal decompression techniques, including "bilateral" percutaneous nephrostomy tubes and "bilateral" nephroureteral stents, in a patient with crossed fused inferior renal ectopia with bilateral ureteral obstruction due to metastatic prostate adenocarcinoma. The outcome for this patient was comparable to patients with normal renal anatomy suggesting that traditional image-guided renal decompression techniques can have similar efficacy in patients with crossed fused inferior renal ectopia.

Competing interests: Dr. Bhojwani, Mr. Hartman, Dr. Ahmed, Mr. Morgan and Dr. Davidson declare no competing financial or personal interests.
This paper has been peer-reviewed.

\section{References}

1. Patel TV, Singh AK. Crossed fused ectopia of the kidneys. Kidney Int 2008;73:662. http://dx.doi. org/10.1038/si.ki.5002418

2. Nariculam J, Murphy DG, Jenner C, et al. Nephrostomy insertion for patients with bilateral ureteric obstruction caused by prostate cancer. Br J Radiol 2009;82:571-6. http://dx.doi.org/10.1259/bir/38306763

3. Abeshouse BS, Bhisitkul I. Crossed renal ectopia with and without fusion. Urol Int 1959;9:63-91. http:// dx.doi.org/10.1159/000277442

4. Solanki S, Bhatnagar V, Gupta AK, et al. Crossed fused renal ectopia: Challenges in diagnosis and management. J Indian Assoc Pediatr Surg 2013;18:7-10. http://dx.doi.org/10.4103/0971-9261.107006

5. Soni HC, Jadav VJ, Sumariya B, et al. Primary malignancy in crossed fused ectopic kidney. Abdom Imaging 2012;37:659-63. http://dx.doi.org/10.1007/s00261-011-9824-8

6. Rinat C, Farkas A, Frishberg Y. Familial inheritance of crossed fused renal ectopia. Pediatr Nephrol 2001;16:269-70. http://dx.doi.org/10.1007/s004670000540

7. Kouba E, Wallen EM, Pruthi RS. Management of ureteral obstruction due to advanced malignancy: Optimizing therapeutic and palliative outcomes. J Urol 2008; 180:444-50. http://dx.doi.org/10.1016/i. juro.2008.04.008

8. Shekarriz B, Shekarriz H, Upadhyay J, et al. Outcome of palliative urinary diversion in the treatment of advanced malignancies. Cancer 1999;85:998-1003. http://dx.doi.org/10.1002/(SICI) 10970142(19990215)85:4<998::AID-CNCR30>3.0.C0;2-F

9. Ishioka J, Kageyama $Y$, Inove $M$, et al. Prognostic model for predicting survival after palliative urinary diversion for ureteral obstruction: Analysis of 140 cases. J Urol 2008;180:618-21; discussion 621. http://dx.doi.org/10.1016/i.juro.2008.04.011

10. Bodner $D$, Kursh $E D$, Resnick MI. Palliative nephrostomy for relief of ureteral obstruction secondary to malignancy. Urology 1984;24:8-10. http://dx.doi.org/10.1016/0090-4295(84)90376-5

Correspondence: Dr. Nicholas Bhoiwani, Department of Radiology, University Hospitals Case Medical Center, 11100 Euclid Ave., Cleveland, OH 44106; nbhoj08@gmail.com 